\title{
Choice of solar share of a hybrid power plant of a central receiver system and a biogas plant in dependency of the geographical latitude
}

\author{
Spiros Alexopoulos ${ }^{1, *}$, Bernhard Hoffschmidt ${ }^{1}$, Christoph Rau ${ }^{1}$, Johannes Sattler ${ }^{1}$ \\ ${ }^{1}$ Solar-Institut Jülich, University of Applied Sciences Aachen, Jülich,Germany \\ *Tel: +49 241600953551, Fax: +49241600953570, E-mail: alexopoulos@sij.fh-aachen.de
}

\begin{abstract}
The potential of renewable energies varies significantly from North to South Europe. Southern Europe has a high solar potential and is ideal for the implementation of solar concentrated power plants. To this group of solar thermal power systems belong the solar tower, parabolic trough, solar dish and linear Fresnel systems. North European countries, especially the Scandinavian countries, have a high biomass and hydropower potential. This paper focuses on calculation of the power production for hybrid systems of solar tower with gas turbine in Southern Europe and biogas-only operation in Northern Europe.

The solar tower system consists of a heliostat field, which concentrates direct solar irradiation on an open volumetric central receiver. The receiver heats up ambient air to temperatures of around $700^{\circ} \mathrm{C}$. The hot air's heat energy is transferred to a steam Rankine cycle in a heat recovery steam generator (HRSG). The steam drives a steam turbine, which in turn drives a generator for producing electricity. In order to increase the operational hours of a solar tower power plant, a heat storage system and/ or hybridization may be considered.

The advantage of solar-fossil hybrid power plants, compared to solar-only systems, lies in low additional investment costs due to an adaptable solar share and reduced technical and economical risks. On sunny days the hybrid system operates in a solar-only mode with the central receiver and on cloudy days and at night with the gas turbine only. As an alternative to methane gas, environmentally neutral biogas can be used for operating the gas turbine. Hence, the hybrid system is operated to $100 \%$ from renewable energy sources.

An advanced software tool library has been developed for modelling such solar hybrid power plants. This library includes the components of the solar-heated hot gas cycle and the steam cycle. Moreover, a choice of different gas turbine and duct burner components is given. When developing a simulation model for the calculation of a small hybrid power plant, components from the library are inserted into the model. The software tool features the possibility of either calculating the energy output of individual operating points or of time intervals in the range of days up to an entire year.

With this simulation tool, hybrid solar tower systems are calculated for various locations with high solar potential within Europe. In addition, locations in North Scandinavian countries with high biomass potential are investigated and power plants with biogas as fuel without solar input are calculated.
\end{abstract}

Keywords: solar tower, central receiver, hybridization, biogas, renewable energy

\section{Introduction}

The potential of renewable energies varies significantly from North to South Europe. Southern Europe has a high solar potential and is ideal for the implementation of solar concentrated power plants. North European countries, especially the Scandinavian countries, have a high biomass and hydropower potential.

Since 1980s, power production with solar thermal power plants and the increasing use of biogas has been a promising option for reducing the consumption of fossil fuels.

The development of solar thermal technologies has gone into many directions, which can be exemplified with the various heat transfer media that are deployed in existing systems. Many solar thermal power plants contribute to the electricity generation in various European countries. To this group of solar thermal power plants belong the solar tower, parabolic trough, solar dish and linear Fresnel systems. Parabolic trough and solar tower systems are the most developed technologies as well as the most economical solar thermal plants at this moment of time. 
A solar tower consists mainly of a heliostat field, a central receiver and a conventional steam Rankine cycle. Various central receiver technologies have been developed throughout the world. The software tool described in this paper models a solar tower with a open volumetric receiver. This type receiver has been deployed in the Solar Tower Jülich (STJ), Germany, since its completion in 2008. The subsequent explanations are valid for this type receiver only. At the STJ, the heliostat field, a field of sun-tracking mirrors, reflects and concentrates the direct solar irradiation onto the open volumetric receiver. This receiver consists of porous ceramic absorber modules. Incident sun rays enter the porous receiver, are absorbed inside and heat it up. To remove the heat, ambient air is continuously sucked through the porous receiver and is heated up to almost $700^{\circ} \mathrm{C}$. The hot air is passed through a heat recovery steam generator (HRSG) in which it passes its heat to a water-steam cycle. The steam is expanded in a steam turbine and the rotation of the turbine's shaft drives a generator to produce electricity. Utilization of air as heat transfer fluid (HTF) secures a high plant efficiency due to the reason that air can be heated to very high temperatures, which in turn enables higher steam temperatures in the Rankine cycle and thus a better Carnot efficiency. Moreover, it allows a fast start-up to operating conditions; it is non-toxic and is available at no costs in unlimited amounts.

In order to increase the operational hours of a solar tower power plant, a heat storage system and/ or hybridization e.g. with biofuels must be considered.

As an alternative to methane gas, environmentally neutral biogas can be used as fuel for operating a gas turbine. Hence, the hybrid system is operated to $100 \%$ from renewable energy sources. The gas turbine not only delivers electricity but also heat in the waste gas, which can be reused.

\section{Methodology}

This paper focuses on the calculation of different important characteristic quantities, which include the annular power production, the solar share and the annual fuel consumption. The combination of two renewable technologies, namely biogas and solar concentrated energy, is investigated. Therefore the operation of a hybrid system consisting of a solar tower power plant and biogas-fuelled gas turbine is investigated.

\subsection{Considered technologies}

\subsubsection{Solar tower plant}

Germany's first solar tower power plant, which has a rated power output of $1.5 \mathrm{MW}_{\mathrm{e}}$, was constructed and completed in 2008 in the town of Jülich [1]. It commenced solar operation in spring of 2009. The plant was built by the general contractor Kraftanlagen München and is operated by the local utility Stadtwerke Jülich. The Solar-Institut Jülich (SIJ) and the German Aerospace Center (DLR) conduct the accompanying research. The project is funded by the economic ministries of the German states of Northrhine-Westphalia and Bavaria, as well as by the German Federal Ministry for the Environment, Nature Conservation and Nuclear Safety.

The objective of the power tower project in Jülich is to demonstrate the entire system in commercial-like operation over a longer period of time, to develop control and plant management strategies and to further improve performance and reliability of the key components. Jülich was chosen as the favoured location because it is situated close to the involved research institutions and due to its fluctuating direct solar irradiation conditions. The latter reason has the advantage that it allows and requires the investigation into the system 
operation strategy under transient conditions, especially with regard to optimizing the charging and discharging process of the thermal storage [2].

\subsubsection{Biogas}

Biogas is produced by the biological breakdown of organic matter in the absence of oxygen. It can be produced by anaerobic digestion or the fermentation of biodegradable materials such as biomass, manure or sewage, municipal waste, green waste and energy crops. Biogas is composed of $45-85 \%$ methane and $15-45 \%$ carbon dioxide, depending on the conditions during production. Moreover, biogas comprises small amounts of hydrogen sulphide, ammonia and nitrogen. Its field of application includes combustion engines, burners as well as gas turbines for electricity generation and co-generation of heat and power. Biogas can be further enhanced from low-quality to natural gas quality before it is fed in the public gas grid. This article considers biogas-fuelled gas turbines only.

\subsubsection{Biogas potential}

In all Scandinavian countries, biomass has a high potential. In the TRANS-CSP study [3] the theoretical potential of biomass is estimated for Norway at $26 \mathrm{TWh} / \mathrm{a}$, for Sweden at $80 \mathrm{TWh} / \mathrm{a}$ and for Finland at 54 TWh/a.

Taking Sweden as an example, the country has approximately 233 biogas facilities with a total biogas production of $1.3 \mathrm{TWh} / \mathrm{a}$ [4]. Biogas can be produced at large-scale centralized plants, where different feed stocks materials are digested, and at small farm-based plants, which use and digest mainly agricultural feed stocks.

The theoretical potential of biogas production in Sweden lies at around 14-17 TWh/a, which is more than 10 times that of the present annual production [5]. From the feed stocks materials $70 \%$ is manure and farm waste, $13 \%$ is industrial waste, $9 \%$ is household waste and the remainder is garden waste and sewage sludge.

For Italy, the best biogas performance is recorded in the northern part of the country especially in the regions of Lombardy, Emilia Romagna, Trentino A.A, Veneto and Piedmont. With a share of 23.8\%, the region of Lombardy is the biggest producer of biogas in Italy and dominates the biogas market. Moreover, Lombardy has the biggest biogas potential, which is estimated at 4,643 GW. As for the production of biogas from manure, 3,800,000 pigs and $1,600,000$ heads of cattle were counted for the region of Lombardy in the ISTAT census in 2001. Together this amounts to $44 \%$ of the total domestic animal breed in Italy [6].

\subsubsection{Hybrid system}

To improve the availability and the capacity factor of a solar tower power plant, a hybridization of the plant is considered. In regions with very high irradiation, solar thermal power plants with heat storage facilities can reach a maximum of 3,000 to 4,000 nominal load hours per year. Hybridization, for example with the combustion of biogas, enables the operator to produce electricity day and night for up to 8,600 hours per year. It is expected that such hybrid power plants will have a high potential for the market introduction in the next decade.

The upgrade of a solar tower power with air receiver technology to a hybrid system by combining it with a gas turbine is shown in Fig. 1. 


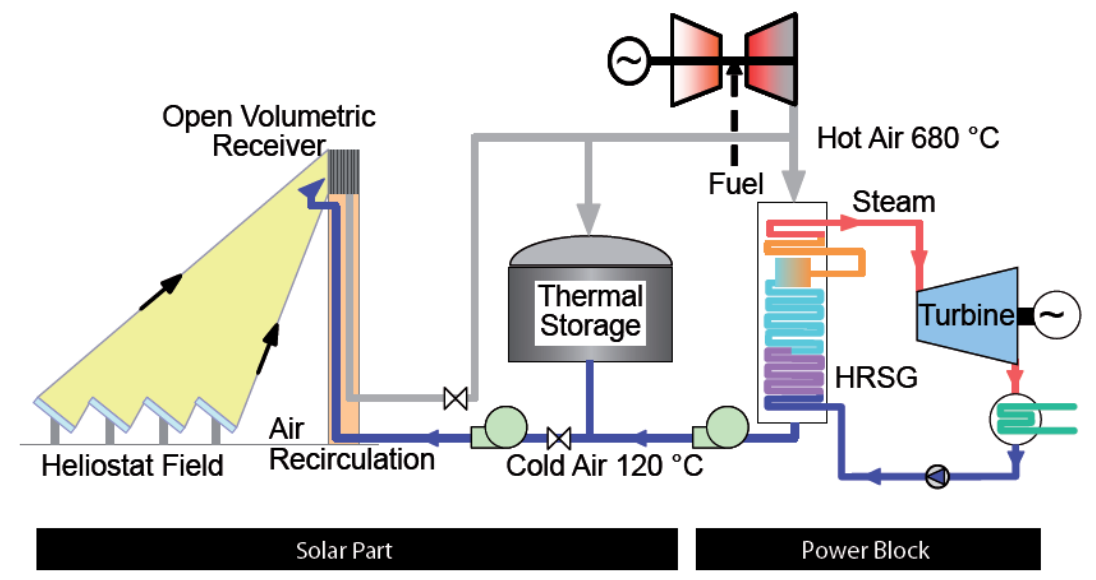

Fig. 1: Schematic diagram of a solar tower demonstration plant hybridised with a gas turbine

The operating strategy for the hybrid plant involves an alternating operation of the gas turbine and the air receiver. On sunny days the air receiver is operated in a solar-only mode. On days with very low direct solar irradiation (very cloudy conditions) the thermal energy provided by the heliostat field is not sufficient for operating the plant. On those days the gas turbine must be operated. The hot exhaust gas from the gas turbine is directed through the heat recovery steam generator (HRSG) for steam generation [7]. Throughout the nights, solely the gas turbine is operated.

\subsection{Simulation}

\subsubsection{Implementation of the model}

The implementation of the solar tower power plant model has been realised in the MATLAB/Simulink environment. MATLAB is a high-performance language for technical computing. It integrates computation, visualization, and programming in an easy-to-use environment, where problems and solutions are expressed in familiar mathematical notation. Simulink is a toolbox in MATLAB that provides an environment for modelling, simulating, and analyzing dynamic systems. It supports linear and nonlinear systems, modelled in continuous time or a sampled time. The implementation of systems can also occur at a multirate, i.e. have different parts that are sampled or updated at different rates [8].

\subsubsection{Model library}

The simulation models are based on thermodynamic theory using assumptions for simplification in order to maintain a fast simulation time while retaining good accuracy. Several components like the steam turbine, generator, burner, solar receiver, heliostat field, etc. are included in the model library. They include mostly energy and mass balance equations as well as additional algebraic equations. Most components models are optimized for steadystate operation. However, components with high thermal inertia, such as a part of the HRSG, are implemented as dynamic models.

The model library (Fig. 2) was developed with consideration of the following characteristics [9]:

- compatibility of the components related to the connection of one to the other

- possibility of choosing different geographical locations for performing the calculations

- applicability for different power plant sizes

- adjustability to different transport media: e.g. air, gas, exhaust gas 
- ease of modification

- usability for short time intervals (minutes)

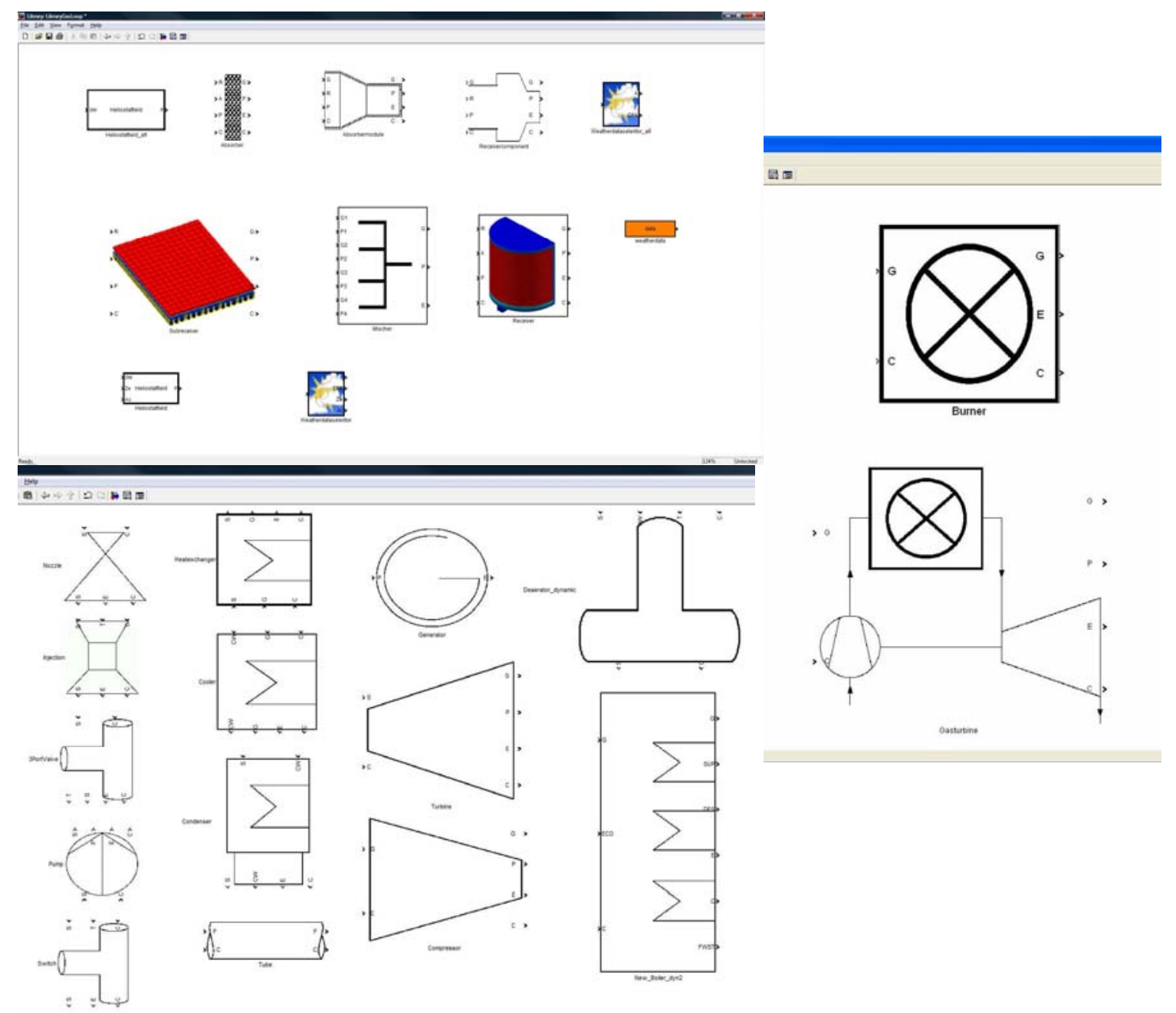

Fig. 2: Model libraries for the steam cycle, the solar and hybridization components

Gas and steam properties can be integrated in each model. The various state variables for water and steam are computed with polynomials taken from the industry standard IAPWSIF97. For calculating the state variables for different gas mixtures, algorithms stated in the VDI (Verein Deutscher Ingenieure - engl.: Association of German Engineers) guideline 4670 [10] and provided by NASA Technical Memorandum 4513 [11] are integrated.

With the developed software, the annual performance and the electrical power output of small solar hybrid tower plants, combined cycle with gas turbine and solar-only operated solar tower with or without storage can be calculated.

\subsubsection{Validation of library components}

The components of the model library were validated mainly with calculation results of other simulation software [12]. They were also verified with results from different design points. The three thermodynamic cycles, namely the steam, air and water cooling cycle, were tested separately before they were combined to a complete power plant system. 


\section{Results}

A comparison of energy production and fuel consumption was made for a combined-cycle plant in Sweden and a hybrid solar tower power plant located both in Jülich and North Italy. The combined-cycle plant in Sweden was taken as reference. It operates with a gas turbine, which utilizes biogas as fuel. The selected gas turbine is a Centrax 501-KB3 [13], which generates a nominal power of $2.68 \mathrm{MW}_{\mathrm{e}}$. The hot exhaust gases are directed through a boiler for steam generation. In the steam cycle, the steam is expanded in a steam turbine. The generator, which is driven by the steam turbine, produces an additional $1.34 \mathrm{MW}_{\mathrm{e}}$.

For all states and power plants, the biogas is composed of 56\% methane, $40 \%$ carbon dioxide and other constituents. The configurations and main simulation parameters are shown in Table 1.

Table 1. Main simulation parameters

\begin{tabular}{cccc}
\hline Place & Scandinavia & Jülich & Northern Italy \\
\hline Nominal Power GT [MW $]$ & 2.68 & 2.68 & 2.68 \\
Nominal Power ST [MW $]$ & 1.34 & 1.50 & 1.50 \\
Heliostats [-] & 0 & 2,150 & 2,150 \\
Mirror area [m ${ }^{2}$ ] & - & 8 & 8 \\
Maximum air/flue gas & & & 680 \\
temperature [ $\left.{ }^{\circ} \mathrm{C}\right]$ & 571 & & 680 \\
\hline
\end{tabular}

Original weather data has been used for the locations Jülich and Milano (Italy). For Jülich, data from the year 2007 in a time resolution of 15 min was integrated. For Milano, data of the year 2006 in a one hour resolution has been used. The quasi-steady-state simulations are computed in time steps of maximum 60 seconds. The steam turbine and generator of the steam cycle for both locations have a generation capacity of about $1.5 \mathrm{MW}_{\mathrm{e}}$. For the hybrid mode, the same gas turbine as simulated for the combined-cycle plant in Sweden $\left(2.68 \mathrm{MW}_{\mathrm{e}}\right)$ was integrated.

The calculation for the location in Scandinavia (Sweden) was performed for a nominal plant operation with 8,760 hours of gas turbine operation. For the hybrid solar tower power plants, the calculation was realized with alternating operating mode. Hence, in the solar-only mode, nominal parameters could not always be reached. The results presented in Table 2 have an estimated error of about $\pm 10 \%$.

Table 2. Simulation results for the three sites.

\begin{tabular}{ccc}
\hline Place & Energy Production [GWh] & Fuel Consumption [t] \\
\hline Scandinavia & 35.21 & 20,385 \\
Jülich & 25.17 & 14,004 \\
Northern Italy & 21.30 & 11,761 \\
\hline
\end{tabular}

The results show that a Conventional Combined Power Plant in Scandinavia generates the estimated energy of $35.21 \mathrm{GWh}$ at a fuel consumption of 20,385 t. The hybrid solar tower power plants instead produce less electrical energy, because only the steam turbine generates energy in daytime. Thus again means, that also less fuel is consumed. The difference between the two locations Jülich and Italy reflects this coherence. Locations with high insolation are associated with the less fuel consumption and less electricity production. This effect occurs if an alternate hybrid operation is considered. 
In Fig. 3, which shows a good day regarding solar radiation (DNI), a typical operation of the hybrid plant in alternate mode is illustrated. The specific electrical (index EL) power of the steam turbine resp. gas turbine are shown. Furthermore, the thermal (index TH) power of the receiver (index Rec) and the heat input at the HRSG (index HRSG).

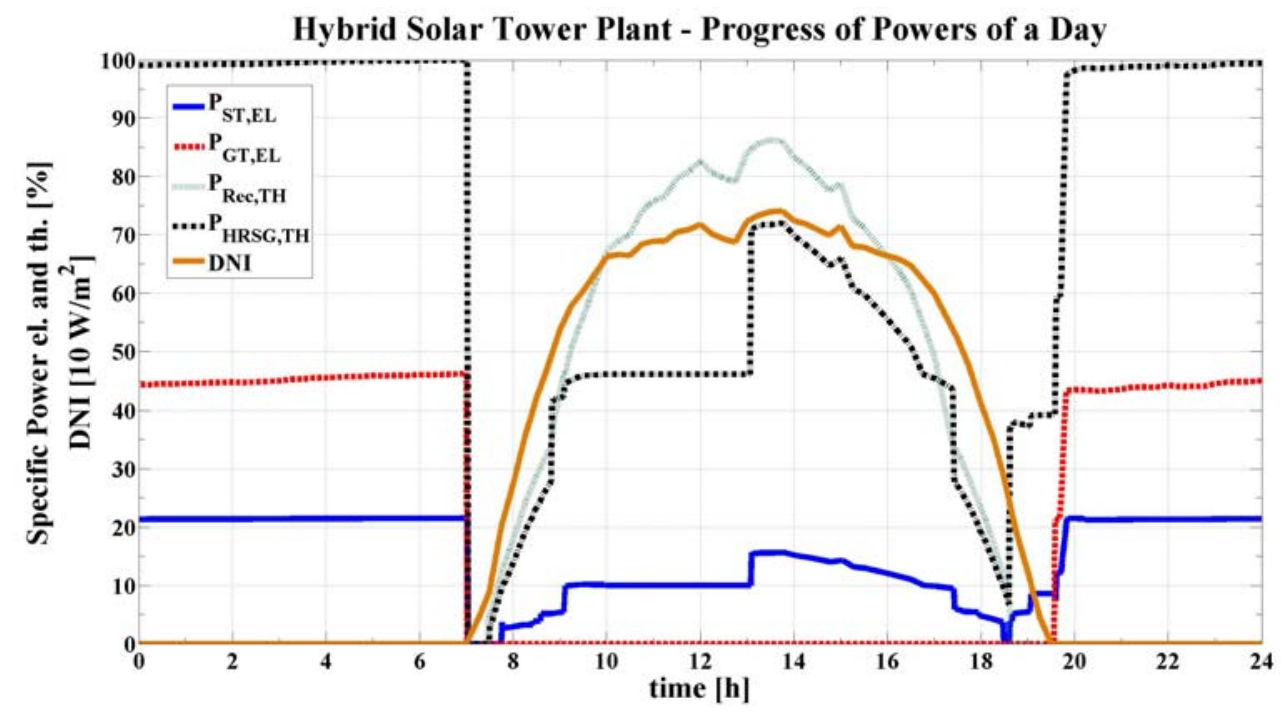

Fig. 3: Hybrid solar power tower plant operation for the $27^{\text {th }}$ March 2007

At night the gas turbine provides continuous electricity and heat to the HRSG, so that a combined-cycle operation is conducted. When solar irradiation increases the gas turbine is shut down. Because of the clear switch to solar operation the electricity generation by the steam turbine may diminish. When solar radiation increases the electricity production increases, too. At a certain stage, by the receiver produced heat is send to the storage. The heat input to the HRSG is kept constant. When the storage is charged to a certain level, the charging is terminated and the full heat input is provided by the receiver (cf. fig 3 . Jump at 13 h). When the sunset starts the storage is discharged slowly and the heat for the HRSG is supplied by the storage. In the evening the shift from storage operation to gas turbine operation is executed. This demonstrated operation strategy needs still optimization to ensure a maximum yield of power production and a continuous operation. Therefore weather dependent operation strategies and controlling has to be developed.

\section{Discussion and Conclusions}

Numerical procedures should be applied for the calculation of the annual energy yield of solar tower power plants. With the simulation tool, hybrid solar towers at different locations with high solar potential in Europe are calculated. Moreover, locations with high biogas potential in North Scandinavian countries are considered and power plants with biogas as fuel without solar input are investigated. The results of the simulation analysis show that the created model library is a solid basis for the simulation of hybrid concepts for solar tower systems.

In next steps a detailed investigation and analysis of the simulation results is planed. The simulation models and especially the operation strategies will be optimized in order to get even more accurate results.

In further steps an additional site in South Europe, for example in South Italy on the island of Sicily, will be investigated. For that reason weather data will be selected and a solar-only operation of a solar tower power plant will be regarded. 


\section{Acknowledgments}

The authors gratefully acknowledge the financial support of the German Federal Ministry for the Environment, Nature Conservation and Nuclear Safety (BMU), the ministries of economic affairs of the German states of North Rhine-Westphalia (NRW) and Bavaria in the solar tower demonstration project. The research into hybridization is supported by the German Federal Ministry of Education and Research (BMBF).

\section{References}

[1] K. Hennecke, P. Schwarzbözl, S. Alexopoulos, J. Göttsche, B. Hoffschmidt, M. Beuter, G. Koll, T. Hartz: SOLAR POWER TOWER JÜLICH The first test and demonstration plant for open volumetric receiver technology in Germany, Proceedings of the 14th Biennial CSP SolarPACES Symposium, Las Vegas, Nevada, 4-7 March 2008, London.

[2] Alexopoulos, S., Goettsche, J., Hoffschmidt, B., Rau, C., Sattler, J., Schmitz, M., Warerkar, Sh., Hennecke, K., Schwarzboezl, P., Beuter, M., Koll, G., Hartz Th. (2009): SOLAR TOWER POWER PLANT JUELICH First experience with an open volumetric receiver plant and presentation of future enhancements, Proceedings Renewable Energy World Europe Conference, Cologne, Germany.

[3] Trans-Mediterranean Interconnection for Concentrating Solar Power, DLR, 2006

[4] Swedish energy agency. Production and use of biogas, 2005.

[5] Lantz, M., Svensson, M., Björnsson, L., Börjesson, P.: The prospects for an expansion of biogas systems in Sweden: Incentives, barriers and potential, Energy policy, 35:18301843, 2007

[6] Ceriani, A.: “Le energie alternative e rinnovabili in Lombardia nell'ambito delle attivià produttive”, Instituto Regionale di Ricerca Della Lombardia, Milan, January, 2010

[7] S. Alexopoulos, B. Hoffschmidt, C. Rau, P. Schwarzbözl: Simulation results for a hybridization concept of a small solar tower power plant, SolarPACES Symposium, Berlin, 15-18 September 2009

[8] MATLAB/Simulink Manual, http://www.mathworks.com, 2010

[9] S. Alexopoulos, B. Hoffschmidt, C. Rau, M. Schmitz, P. Schwarzbözl, S. Pomp: Simulation results for a hybridised operation of a gas turbine or a burner for a small solar tower power plant, SolarPACES Symposium, Perpignan, France, 21-24 September 2010

[10] McBride, B. J., Gordon, S., Reno, M. A.: Coefficients for calculating thermodynamic and transport properties of individual species, Nasa Technical Memorandum 4513, 1993

[11]VDI: Thermodynamische Stoffwerte von feuchter Luft und Verbrennungsgasen - VDI 4670, 2003

[12] S. Alexopoulos, B. Hoffschmidt, J. Göttsche, C. Rau, P. Schwarzbözl: First simulation results for the hybridization of small solar power tower plants, 1st International Conference on Solar Heating, Cooling and Buildings, Lisboa, Portugal, 7-10 October 2008

[13] ASUE - Arbeitsgemeinschaft für sparsamen und umweltfreundlichen Energieverbrauch E.V.: Gasturbinen-Kenndaten-Referenzen, 2006 